\title{
Inhibition of the Ras/Raf/extracellular signal-regulated kinase 1/2 signaling pathway by compounds of natural origin for possible treatment of spinal cord injury: An in silico approach
}

\author{
SHILEI YAN, LI ZHANG, SHUAI WANG, TIANHAO WU and ZHIXIN GONG
}

Department of Orthopedic Surgery, The Third Hospital of Hebei Medical University, Shijiazhuang, Hebei 050051, P.R. China

Received January 24, 2017; Accepted July 27, 2017

DOI: $10.3892 / \mathrm{etm} .2018 .5734$

\begin{abstract}
Spinal cord injury (SCI) is a severe disease associated with permanent neurological deficit. Recent studies in the treatment of SCI have demonstrated that the Ras/Raf/extracellular signal-regulated kinase 1/2 (ERK1/2) signaling pathway serves an important role in the disease etiology, and that upregulation of this signaling pathway is associated with the development of SCI. In the present study, inhibition of Ras protein was employed in order to downregulate the Ras/Raf/ERK1/2 signaling pathway using compounds of natural origin from the Interbioscreen natural compound database. To the best of our knowledge, this is the first study using a chemical-computational approach in order to identify novel small molecule inhibitors for Ras. A database of $\sim 50,000$ compounds was selected for virtual screening, setting a free energy binding bias of $-7 \mathrm{kcal} / \mathrm{mol}$ to limit the number of compounds. The subset of compounds generated by virtual screening was further limited by subjecting these to the Lipinski's rule of five parameters. A total of five shortlisted compounds were subjected to molecular docking simulation. The compounds were docked into the GTP binding site of Ras, and the inhibition of this site was examined as a promising strategy for the downregulation of Ras/Raf/ERK1/2 signaling pathway. The compounds bound to the GTP binding site through hydrogen bonds and hydrophobic interactions. The identified lead compound was then subjected to molecular dynamics simulation, and the results revealed that GLY60 in the GTP binding site of Ras protein was the optimal binding site during a $100 \mathrm{nsec}$ run.
\end{abstract}

\section{Introduction}

Spinal cord injury (SCI), an event associated with permanent neurologic deficit $(1,2)$, is reported to affect $10-40 /$ million

Correspondence to: Dr Zhixin Gong, Department of Orthopedic Surgery, The Third Hospital of Hebei Medical University, 139 Ziqiang Road, Shijiazhuang, Hebei 050051, P.R. China

E-mail: gongzhixin68@hotmail.com

Key words: spinal cord injury, natural compounds, Ras inhibitor, virtual screening, molecular docking, molecular dynamics simulation individuals annually in developed countries (3). In the United States, there are $\sim 253,000$ cases of SCI, with $\sim 11,000$ new cases diagnosed annually (3). The economic cost of this disease in the United States alone is estimated to be billions of dollars (4). Violence and accidents are the two causes of SCI, with $26 \%$ of cases associated with violence and the remaining associated with accidents (5).

The first mention of SCI is recorded to be in $1700 \mathrm{BC}$ in the Edwin Smith Papyrus, an Egyptian medical text, describing this disease as an 'ailment not to be treated', which demonstrates the severity of SCI as it was considered an untreatable ailment (6). SCI is a severe condition, with mortality occurring in the majority of patients prior to any primary hospital care, while patients treated at the hospital are prone to morbidity and mortality (5). Neurological deficit and disabilities resulting from SCI not only affect the sensory and motor capabilities, but also has a strong impact on the physiological condition of the patient (7). SCI is categorized into primary SCI, defined as the damage inflicted at the time of trauma, and secondary SCI, which is defined as the body's response to the initial trauma (8).

Due to the significant decrease in the quality of life of patients following SCI, investigation of the pathophysiology and treatment of this disease is urgent. To date, studies have focused on preventing secondary SCI, promoting regeneration and replacing the destroyed spinal cord tissue $(9,10)$. Methylprednisolone is the only current agent approved for the treatment of primary SCI that is widely used, although it presents selective/limited efficacy and significant side effects (11-15). In order to overcome the side effects of this glucocorticoid, the use of poly (lactic-co-glycolic acid) nanoparticle formulations for the encapsulation of methylprednisolone has been used (16). Novel therapeutic strategies are being developed based on the basic approach involving the targeting of the cascading mechanism that leads to secondary SCI (10). In this regard, altering the neuro-inflammation (17), reducing free-radical damage (18), reducing excitotoxic damage to neurons (19), improving the blood flow to the primary injury site (20) and countering the effect of ionic exchange at the primary injury site (21) are the most commonly studied therapeutic strategies.

Estrogen and its analogs have been widely investigated as secondary SCI inhibitors, with previous studies suggesting their anti-apoptotic effects, as well as their role in decreasing the activation of cysteine protease, in the attenuation of vascular endothelial growth factor and in aquaporin 
upregulation (21-24). Estrogen has been reported to aid in the improvement of SCI and promotion of the repair of the damaged spinal cord by modulating the immune response (25). Thus, studies have been conducted on boosting and/or modulating the immune response, and one such approach involved the inhibition of the Ras/phosphatidylinositol 3-kinase (PI3K)/RAC $\alpha$ serine/threonine-protein kinase (Akt)/serine/threonine-protein kinase mTOR (mTOR) signaling pathway $(22,26,27)$.

The involvement of $\mathrm{R}$ as in the sympathetic neuronal survival via the PI3K and dual specificity mitogen-activated protein kinase kinase mek-1 signaling pathway is well established, while its role in suppressing apoptosis by regulating the cellular tumor antigen p53 pathway is known to benefit SCI treatment (28-30). The majority of studies to date have examined the Ras/PI3K/Akt/mTOR pathway as the neuroprotective and neuroregenerative functions in SCI are regulated by this pathway, and rapamycin inhibition of mTOR has been reported to exhibit a positive effect on mice with SCI (31-33). Although the role of the Ras/Raf/extracellular signal-regulated kinase $1 / 2$ (ERK1/2) signaling pathway in cell proliferation, migration, differentiation and death is well documented (34-36), its involvement in the treatment of SCI has not been widely investigated. Studies have revealed that the U0126 inhibitor functions as a potential drug for restoring SCI by affecting spinal cord neurons (SCNs) via altering the Raf/ERK signaling pathway (26,37-39).

The present study attempted to identify a novel natural compound (Lead) involved in the alteration of the Raf/ERK pathway for the regeneration of SCNs following SCI. The study used the Interbioscreen (IBS) natural compound database (www.ibscreen.com) consisting of 48,531 natural compounds, known to be largest collection of natural compounds, their derivatives and mimetics worldwide. A multistep structure-based virtual screening technique, followed by docking and simulation, was employed for identifying a promising lead compound, which is a widely used method for identifying such compounds (40-42).

\section{Materials and methods}

Protein and compounds of natural origin dataset preparation. The atomic coordinates for the Ras [Protein Data Bank (PBD) ID, 4LPK] structure required for the development of a lead compound were obtained from the PDB (rcsb. org/pdb/home/home.do). This crystal structure of GTPase KRas is GDP-bound, and the coordinates of this Ras protein were used. The energy-minimization of the structure was performed by using the Swiss-PdbViewer software (version 4.1; Swiss Institute of Bioinformatics, Lausanne, Switzerland). The root mean square deviation (RMSD) was monitored using the GROMOS96 43b1 force field (43). Approximately 48,531 natural compounds from the IBS database were used for targeting the GTP binding site of Ras.

Protein network reconstruction. The Ras/PI3K/Akt/mTOR protein-protein interactions networks were constructed using Cytoscape (version 3.5.1; National Resource of Network Biology, San Francisco, CA, USA). The tool was used for compiling protein functional classification, and physical and genetic interaction networks.
Virtual screening and drug-likeliness prediction. The ArgusLab suit was used for virtual screening of compounds of natural origin (44). In total, $>1 \%$ (414) compounds were shortlisted according to the binding energy $(\Delta \mathrm{G})$ calculations. A $\Delta \mathrm{G}$ of $-7 \mathrm{kcal} / \mathrm{mol}$ was set as the cut off to obtain the initial subset of compounds. This cut off value was a limiting bias set in order to limit the number of compounds, since a $\Delta \mathrm{G}$ of $-8 \mathrm{kcal} / \mathrm{mol}$ provided very few compounds for further investigation and a value of $-6 \mathrm{kcal} / \mathrm{mol}$ provided a very large number of compounds. Thus, $\Delta \mathrm{G}$ was set at $-7 \mathrm{kcal} / \mathrm{mol}$ to provide an acceptable number of compounds for further validation (40-42). The number of selected compounds was then further reduced by subjecting to the rules set by Lipinski (45), which assesed the molecular weight (MW), hydrogen bond acceptor (HBA), hydrogen bond donor (HBD) and octanol/water partition coefficient (cLogP) of each compound. Lipinski's rule of five (RO5) parameters provided five compounds that were subjected to further analysis. Absorption, distribution, metabolism and excretion (ADME) analysis was performed using the PreADME/T online server (preadmet.bmdrc.kr/adme/).

Molecular docking analysis. A structure-based drug designing method was used by employing the AutoDock 4.2 tool for molecular docking analysis (46). This tool calculates energy values by classification into internal and torsional free energy. The internal energy is the sum of the desolvation, hydrogen bonding, van der Waals and electrostatic energies. The Lamarckian genetic algorithm default parameters (46) were used for calculating the $\Delta \mathrm{G}$ of each shortlisted compound. A grid box (40x40x40 ̊) was built around the GTP binding site. Energy values were generated and the binding mode with the GTP binding site was used to limit the investigated compounds to a single molecule.

Molecular dynamics simulation (MDS). The single compound shortlisted was simulated for 100 nsec using MDS, which was conducted using the GROMACS suit (47). From the compounds initially identified, molecular docking identified the optimal compound as lead3, which was then studied using MDS. To mimic in vitro conditions, the Ras-Lead3 complex was kept in an in silico neutral (no charge) water bath, where a water molecule was represented by a simple point charge (SPC216). GROMOS 43a1 force field for Ras was used for simulation, and the force field for the compound was calculated using the PRODRG server (48). Energy minimization procedures for $1 \mathrm{nsec}$ were performed using canonical [number of particles, volume and temperature (NVT) are held constant] and isothermal-isobaric [N, pressure and T (NPT) are held constant] ensembles. In NVT and NPT ensembles the coupling scheme of Berendsen, SHAKE algorithm and particle mesh Ewald method were used (49-51). Next, the energy-minimized Ras-Lead3 complex was simulated for $100 \mathrm{nsec}$, and the trajectories generated were subjected to Molecular Mechanics Poisson-Bolzmann Surface Area (MM-PBSA) calculations. The g_mmpbsa tool developed for GROMACS, which was used for principal component analysis (PCA) (52). Snapshots of the coordinates and the total energies were obtained after 500 psec, while 501 snapshots of the RAS-Lead3 complex were also subjected to the MM-PBSA 


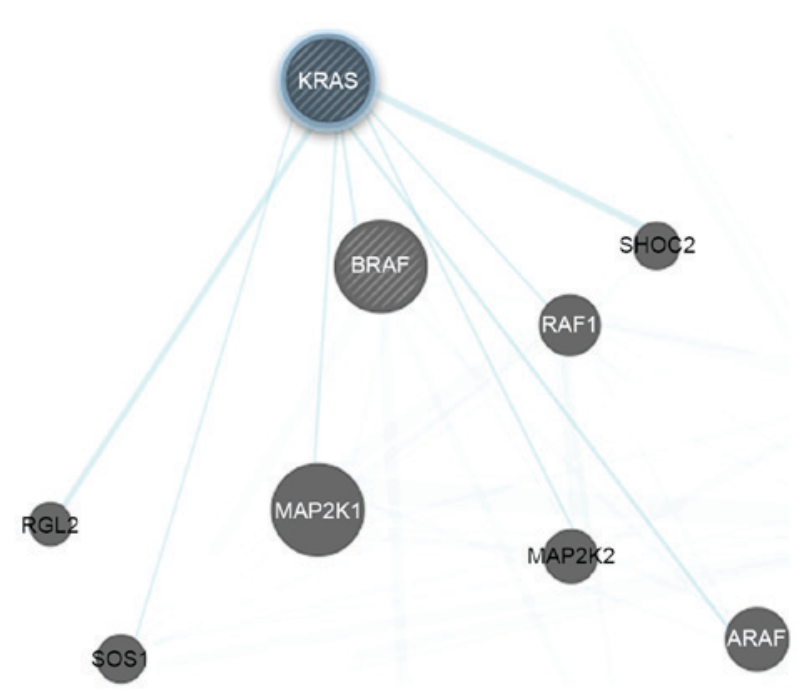

Figure 1. Protein subnetworks of Ras (the query protein) with Raf and ERK1/2. The subnetworks were generated by Cytoscape software. ERK1/2, extracellular signal-regulated kinase 1/2. KRAS, GTPase KRas; BRAF, serine/threonine-protein kinase B-raf; MAP2K, dual specificity mitogen-activated protein kinase kinase; $\mathrm{SHOC} 2$, leucine-rich repeat protein SHOC-2; RAF1, RAF proto-oncogene serine/threonine-protein kinase; ARAF, serine/threonine-protein kinase A-Raf; SOS1, son of sevenless homolog 1; RGL2, DELLA protein RGL2.

calculation. The binding free energy $\left(\Delta \mathrm{G}_{\text {bind }}\right)$ was composed of the following species:

$$
\begin{gathered}
\Delta \mathrm{G}_{\text {bind }}=\mathrm{G}_{\text {complex }}-\mathrm{G}_{\text {protein }}-\mathrm{G}_{\text {ligand }}=\Delta \mathrm{E}_{\mathrm{MM}}+\Delta \mathrm{G}_{\mathrm{sol}}-\mathrm{T} \Delta \mathrm{S} \\
\Delta \mathrm{E}_{\mathrm{MM}}=\Delta \mathrm{E}_{\mathrm{val}}+\Delta \mathrm{E}_{\text {ele }}+\Delta \mathrm{E}_{\mathrm{vdw}} \\
\Delta \mathrm{G}_{\mathrm{sol}}=\Delta \mathrm{G}_{\mathrm{p}}+\Delta \mathrm{G}_{\mathrm{np}} \\
\Delta \mathrm{G}_{\mathrm{np}}=\gamma \mathrm{SASA}+\beta
\end{gathered}
$$

In the aforementioned equations, $\mathrm{G}_{\text {complex }}, \mathrm{G}_{\text {protein }}$ and $\mathrm{G}_{\text {ligand }}$ represent the free energy of the respective species. $\Delta \mathrm{E}_{\mathrm{MM}}$ refers to the gas phase energy, $\Delta \mathrm{G}_{\mathrm{sol}}$ is the solvation energy, $\mathrm{T} \Delta \mathrm{S}$ represents an entropy term, $\Delta \mathrm{E}_{\mathrm{val}}$ is the sum of the internal energy of bonds, angle and torsion, $\Delta \mathrm{E}_{\text {ele }}$ is the electrostatic interaction, $\Delta \mathrm{E}_{\mathrm{vdw}}$ is the van der Waals interaction energy, $\Delta \mathrm{G}_{\mathrm{p}}$ is the polar salvation free energy, and finally $\Delta \mathrm{G}_{\mathrm{np}}$ refers to the nonpolar salvation free energy.

Molecular visualization analysis. The RAS-Lead3 complex was investigated using the visualization tools Pymol (version 1.8.6.2) (53) and Discovery Studio (version 16.1.015350) (54). For graph construction, the Grace Program (version 5.1.22) (55) and Gnuplot (version 5.0.6) (56) were used.

\section{Results and Discussion}

A database comprised of natural compounds, their derivatives and mimetics were considered in order to identify compounds that would inhibit the Ras/Raf/ERK1/2 pathway by inhibiting the GTP binding site of Ras (Fig. 1). The role of the Ras/Raf/ERK signaling pathway in promoting apoptosis in neural cells in SCI is well established (27). Ras
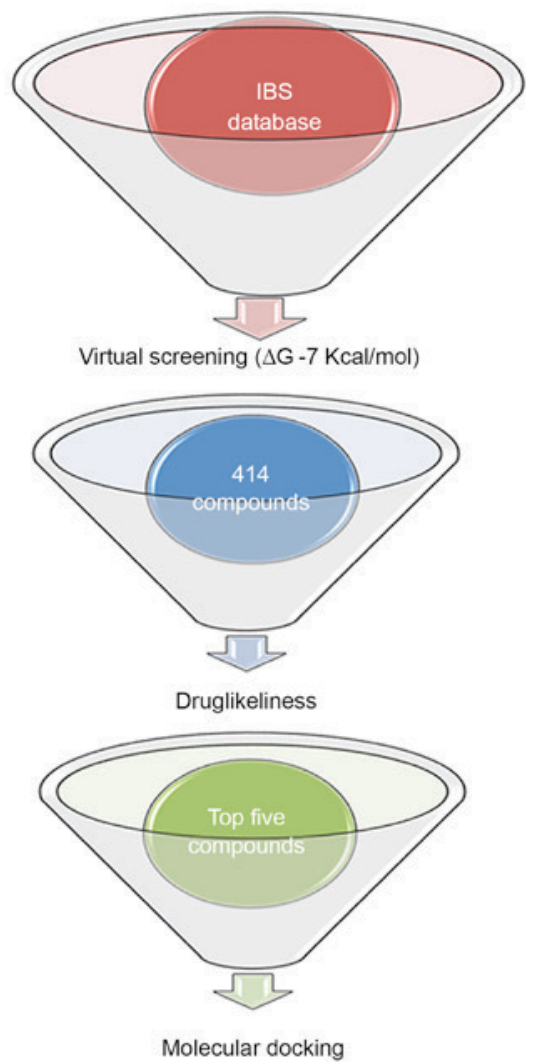

Molecular docking

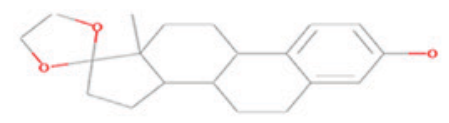

Top lead

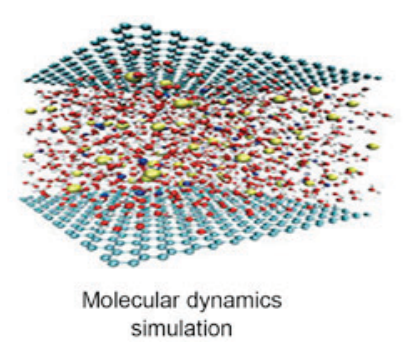

Figure 2. Methodology of the present study, attempting to identify the inhibitor of Ras protein for the downregulation of Ras/Raf/extracellular signal-regulated kinase $1 / 2$ signaling pathway. IBS, Interbioscreen; $\Delta \mathrm{G}$, binding energy.

inhibitors modulate the intracellular signaling of Ras to exhibit a pro-apoptotic or neuroprotective effect (31). The U0126 inhibitor demonstrates a neuroprotective activity by suppressing ERK1/2 activation (57). The consistent evidence on the role of ERK1/2 in neuronal apoptotic cell death provided an opportunity to identify novel small molecule inhibitors using in silico approaches (37). This signaling cascade is triggered by the membrane receptor, which allows Ras to swap GDP for a GTP and to become active. This activated Ras then activates the kinase activity of Raf, which in turn phosphorylates and activates ERKs (ERK1 and ERK2). In the present study, in order to identify a novel Ras inhibitor, virtual screening, drug-likeliness, molecular docking analysis and MDS methods were used, and this methodology is demonstrated in Fig. 2. Virtual screening helped to limit the number 
Table I. Drug-likeliness of top five lead compounds.

\begin{tabular}{lccccccc}
\hline IBS no. & MW & cLogP & HBD, $\mathrm{n}$ & HBA, $\mathrm{n}$ & TPSA & Mutagenicity & Carcinogenicity \\
\hline 05678 & 314.419 & 4.41 & 1 & 3 & 38.69 & No & No \\
46780 & 405.401 & 3.35 & 2 & 7 & 109.57 & No & No \\
49515 & 413.183 & 3.65 & 2 & 7 & 109.75 & No & No \\
49817 & 405.151 & 3.94 & 3 & 8 & 129.28 & No & No \\
64118 & 405.121 & 3.12 & 2 & 6 & 96.28 & No & No \\
\hline
\end{tabular}

cLogP, octanol/water partition coefficient; TPSA, total polar surface area; IBS, Interbioscreen; HBA, hydrogen bond acceptor; HBD, hydrogen bond donor.
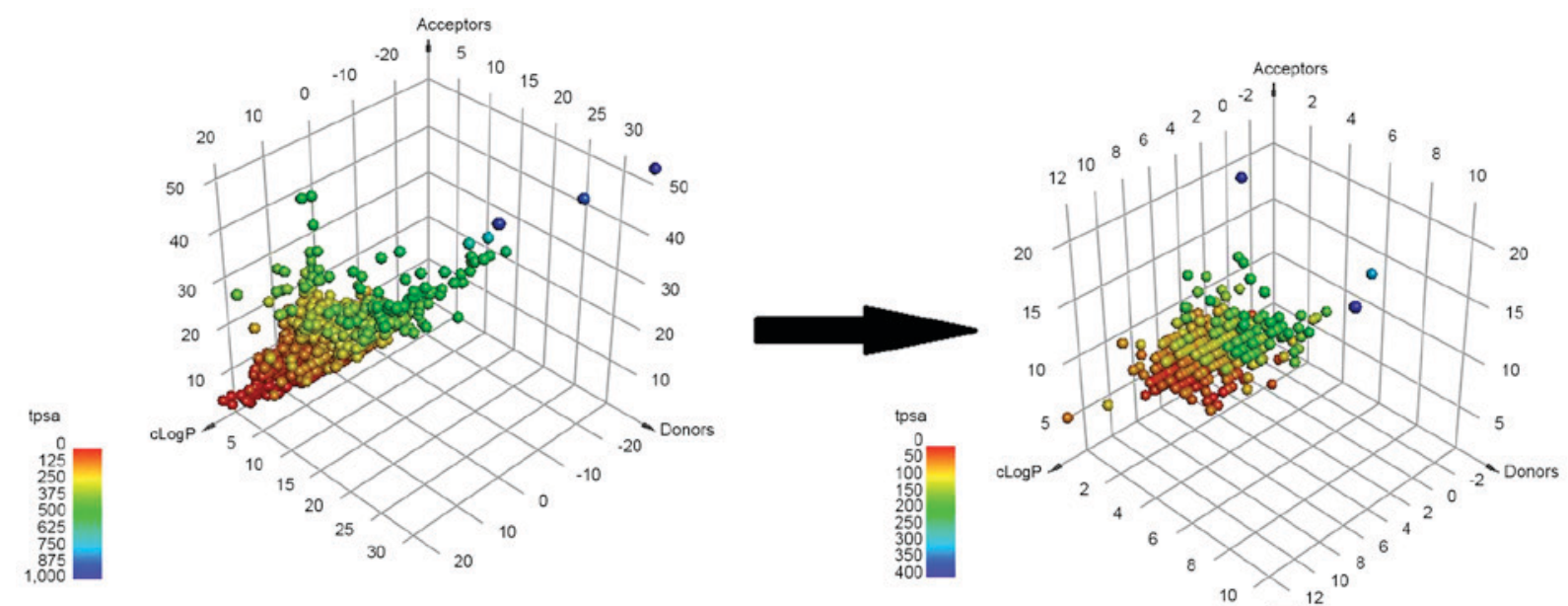

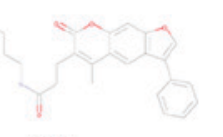

Lead 1
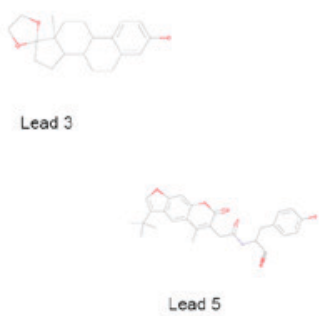

Lead 2
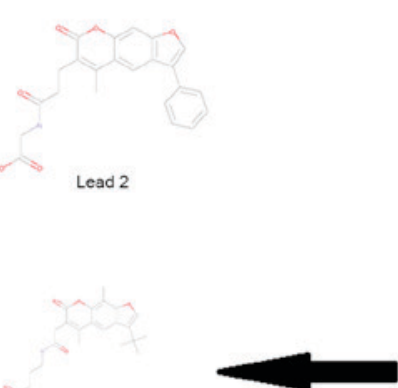

Lead 4
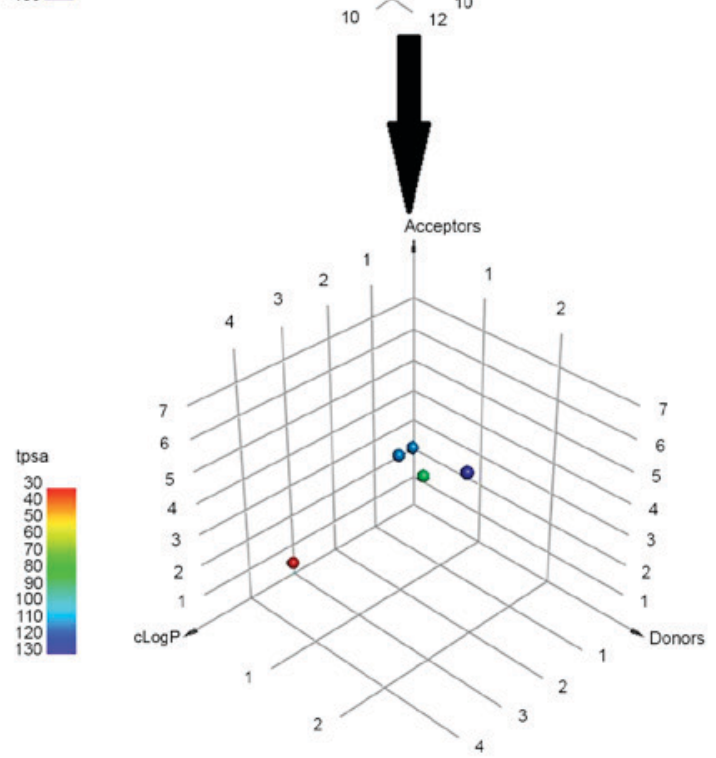

Figure 3. Three-dimensional point plot of the IBS natural product database. The point plot represents the natural products at the virtual screening, drug-likeliness, molecular docking and molecular dynamics simulation stages of the study, demonstrating the final selection of five lead compounds according to Lipinski's rule of five parameters. IBS, Interbioscreen; tpsa, total polar surface area; cLogP, octanol/water partition coefficient.

of compounds from 48,531 natural products to 414 compounds using a limiting bias of $\Delta \mathrm{G}$ of $-7 \mathrm{kcal} / \mathrm{mol}$.

In order to focus on compounds that may be promising for further development, each of the top identified compounds was examined for drug-likeliness. The drug-likeliness of the shortlisted compounds was defined according to the mutagenic and carcinogenic properties, Lipinski's RO5 and total polar surface area (TPSA). The RO5 properties included the number of HBDs and HBAs, the MW and cLogP, with the permissible range being $\mathrm{HBD} \leq 5, \mathrm{HBA} \leq 10, \mathrm{MW} \leq 500 \mathrm{Da}$ and cLogP $\leq 5$. Fig. 3 represents the three-dimensional point plot of the HBA, HBD and cLogP values. The coloring in the figure is according to the TPSA.

Table I demonstrates the drug-likeliness properties of the top five identified compounds. The drug-likeliness values of these compound conformed to the values expected from 
Table II. Absorption, distribution, metabolism and excretion properties calculated by in silico approach.

\begin{tabular}{|c|c|c|c|c|c|c|c|}
\hline Name & IBS no. & Definition & $\begin{array}{l}\text { Caco-2 p } \\
(\mathrm{nm} / \mathrm{sec})\end{array}$ & $\begin{array}{l}\text { MDCK p } \\
(\mathrm{nm} / \mathrm{sec})\end{array}$ & $\begin{array}{l}\text { HIA } \\
(\%)\end{array}$ & $\begin{array}{c}\text { BBB } \\
\text { (c.b/c.bl) }\end{array}$ & $\begin{array}{c}\text { PPB } \\
\text { PPB }(\%)\end{array}$ \\
\hline Lead1 & 64118 & $\begin{array}{l}\mathrm{N} \text {-(3-hydroxypropyl)-3-(5-methyl-7-oxo-3- } \\
\text { phenyl-7H-furo[3,2-g]chromen-6-yl)propanamide }\end{array}$ & 20.79 & 0.14 & 94.97 & 0.052 & 91.18 \\
\hline Lead2 & 46780 & $\begin{array}{l}\text { 2-(3-(5-methyl-7-oxo-3-phenyl-7H-furo[3,2-g] } \\
\text { chromen-6-yl)propanamido)acetic acid }\end{array}$ & 19.14 & 0.09 & 97.82 & 0.012 & 93.02 \\
\hline Lead3 & 05678 & $\begin{array}{l}\text { (13S)-13-methyl-6,7,8,9,11,12,13,14,15,16- } \\
\text { decahydrospiro[cyclopenta[a]phenanthrene- } \\
17,2^{\prime}-[1,3] \text { dioxolan]-3-ol }\end{array}$ & 43.61 & 56.29 & 95.62 & 3.620 & 100.00 \\
\hline Lead4 & 49515 & $\begin{array}{l}\text { 4-(2-(3-(tert-butyl)-5,9-dimethyl-7-oxo-7H-furo } \\
\text { [3,2-g]chromen-6-yl)acetamido)butanoic acid }\end{array}$ & 20.02 & 0.12 & 96.89 & 0.012 & 89.00 \\
\hline Lead5 & 49817 & $\begin{array}{l}\text { (S)-2-(2-(3-(tert-butyl)-5-methyl-7-oxo-7H-furo } \\
\text { [3,2-g]chromen-6-yl)acetamido)-3- } \\
\text { (4-hydroxyphenyl)propanoic acid }\end{array}$ & 21.23 & 0.05 & 95.97 & 0.019 & 89.61 \\
\hline
\end{tabular}

Absorption, distribution, metabolism and excretion properties of top five identified compounds were calculated by the PreADME/T online server. Caco-2 p, Caco-2 cell permeability; MDCK p, MDCK cell permeability; HIA, human intestinal absorption; PPB, plasma protein binding; BBB, blood-brain barrier; IBS, Interbioscreen; c.b., concentration in brain; c.bl., concentration in blood.
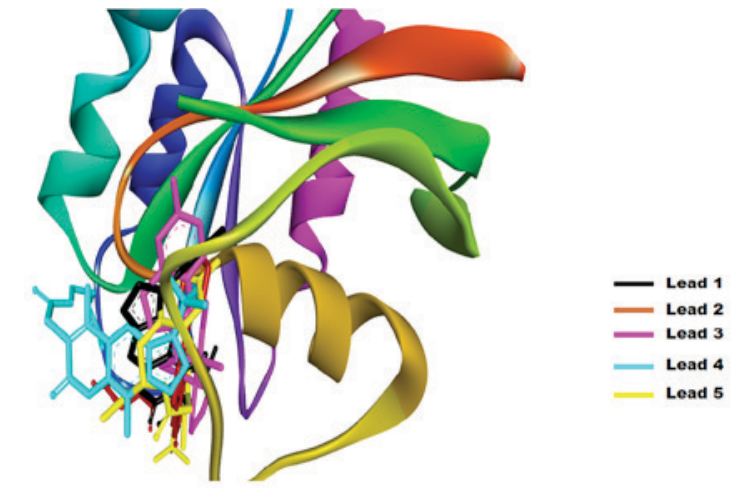

Figure 4. Solid ribbon structure of the GTP binding pocket of Ras with the top five lead compounds identified.

typical drugs. These five compounds where subjected to ADME analysis. In silico methods were used to calculate the Caco-2 cell permeability (Caco-2 p), MDCK cell permeability, human intestinal absorption, plasma protein binding (PPB) and blood-brain barrier (BBB), and the results generated are shown in Table II. The ADME properties of the shortlisted compounds were within the acceptable range for known drugs available in the market.

In the current study, the AutoDock tool was used for molecular docking simulations, selecting the top binding pose based on the $\Delta \mathrm{G}$ for further analysis (Fig. 4). Each binding pose was analyzed using the Discovery Studio software, and the default parameters were used to calculate all the possible interactions. The results generated are listed in Table III, where the $\Delta \mathrm{G}$, binding pocket and number of hydrogen bonds formed are demonstrated. The interactions investigated included the van der Waals, conventional hydrogen bond, carbon hydrogen bond, $\pi$-cation, $\pi$-donor hydrogen bond, alkyl and $\pi$-alkyl interactions. The Lead1-Ras complex presented a $\Delta \mathrm{G}$ of $-6.12 \mathrm{kcal} / \mathrm{mol}$ and the interaction is shown in Fig. 5, where Lead1 is forming two conventional hydrogen bonds with ALA146 and ASN116 of the Ras GTP binding site. The binding pocket of Lead1 comprises following amino acids ALA59, GLY12, PRO34, GLY13, VAL29, PHE28, LEU120, LYS117, ASN116, LYS147, GLY15, ALA18, SER145, ALA146, SER17, ASP57, LYS16 and THR58. The $\mathrm{O}_{23}$ atomic site of Lead1 shows hydrogen bond interaction with ALA146 and ASN 116, with a distance between the Lead and Ras of 2.14 and $1.97 \AA$, respectively.

Lead2 exhibited two conventional hydrogen bond interactions with the GTP binding pocket of Ras. Two atoms of Lead2, $\mathrm{O}_{12}$ andO $_{25}$, formed a bond with TYR32 and ASN85, with a bond length of $2.02 \AA$ and $1.88 \AA$, respectively. In addition, the binding pocket of Lead 2 was comprised of 15 amino acids, as follows: PRO34, TYR32, GLU31, ASP30, PHE28, ALA18, ASN116, LEU120, LYS117, GLY15, ASN85, VAL14, SER17, LYS16 and GLY13. Furthermore, Lead3 exhibited a $\Delta \mathrm{G}$ of $-8.58 \mathrm{kcal} / \mathrm{mol}$, which was the best reported value among the top five shortlisted compounds. The binding pocket of the Lead3 molecule with a GTP binding site of Ras comprises of the following amino acids: GLY60, THR58, SER17, GLY15, TYR32, PHE28, VAL29, ASP30, GLU31, ALA18, LYS117, GLY13, LYS16, PRO34, GLY12 and ALA59. Out of these, Lead3 formed hydrogen bond with GLY60, while the interaction of interest in the present study was formed by the Lead3 $\mathrm{O}_{21}$ position.

Based on the $\Delta \mathrm{G}$ and the number of interactions, Lead4 was ranked last among the top five shortlisted compounds. Its binding pocket was comprised of 11 amino acids, namely: TYR32, GLU31, PRO34, GLY12, ASN86, ASN85, GLY13, LYS117, LYS116, SER17 and ASP33. Lead4 presented a $\Delta G$ of $-5.47 \mathrm{kcal} / \mathrm{mol}$, and had a single hydrogen bond interaction between the Lead4 $\mathrm{O}_{20}$ position and Ras ASN85 (2.07 $⿱$ ). The last Lead compound identified in the current study was termed Lead5, which demonstrated a $\Delta \mathrm{G}$ of $-6.08 \mathrm{kcal} / \mathrm{mol}$ and formed a maximum number of interactions in the GTP 
Table III. Binding pose analysis of top five identified compounds, including calculation of the ligand-binding pocket and the hydrogen bond formation using Discovery Studio.

\begin{tabular}{|c|c|c|c|c|}
\hline Name & IBS no. & $\Delta \mathrm{G}(\mathrm{kcal} / \mathrm{mol})$ & Ligand binding pocket & H-bonds \\
\hline Lead1 & 64118 & -6.27 & $\begin{array}{l}\text { ALA59, GLY12, PRO34, GLY13, VAL29, } \\
\text { PHE28, LEU120, LYS117, ASN116, LYS147, } \\
\text { GLY15, ALA18, SER145, ALA146, SER17, } \\
\text { ASP57, LYS16 and THR58 }\end{array}$ & $\begin{array}{l}\text { ALA146:HN-Lead1:O }{ }_{23}(2.14 \AA) \\
\text { ASN116:HD21-Lead1: } \mathrm{O}_{23}(1.97 \AA)\end{array}$ \\
\hline Lead2 & 46780 & -7.72 & $\begin{array}{l}\text { PRO34, TYR32, GLU31, ASP30, PHE28, } \\
\text { ALA18, ASN116, LEU120, LYS117, GLY15, } \\
\text { ASN85, VAL14, SER17, LYS16 and GLY13 }\end{array}$ & $\begin{array}{l}\text { TYR32:HN-Lead2: } \mathrm{O}_{12}(2.02 \AA) \\
\text { ASN85:HD21-Lead2: } \mathrm{O}_{25}(1.88 \AA)\end{array}$ \\
\hline Lead3 & 05678 & -8.58 & $\begin{array}{l}\text { GLY60, THR 58, SER17, GLY15, TYR32, PHE28, } \\
\text { VAL29, ASP30, GLU31, ALA18, LYS117, } \\
\text { GLY13, LYS16, PRO34, GLY12 and ALA59 }\end{array}$ & GLY60:HN-Lead3:O ${ }_{21}(2.11 \AA)$ \\
\hline Lead4 & 49515 & -5.47 & $\begin{array}{l}\text { TYR32, GLU31, PRO34, GLY12, ASN86, ASN85, } \\
\text { GLY13, LYS117, LYS116, SER17 and ASP33 }\end{array}$ & ASN85:HD21-Lead4:O ${ }_{20}(2.07 \AA)$ \\
\hline Lead5 & 49817 & -6.08 & $\begin{array}{l}\text { ASP119, LEU120, LYS117, ASN116, GLY15, } \\
\text { ALA18, TYR32, PRO34, SER17, GLY13, VAL29, } \\
\text { PHE28, GLU31, LYS147, PHE28 and ASP30 }\end{array}$ & $\begin{array}{l}\text { Lead5: } \mathrm{O}_{32}-\mathrm{SER} 17: \mathrm{OG}(2.58 \AA) \\
\text { SER17:HN-Lead5: } \mathrm{O}_{32}(1.68 \AA)\end{array}$ \\
\hline
\end{tabular}

The atoms involved in hydrogen bond formation are mentioned with their position in subscript. Amino acids shown in bold represent those involved in the formation of hydrogen bond with the compounds. IBS, Interbioscreen; OG, Oxygen group; HD, Hydrogen donor.
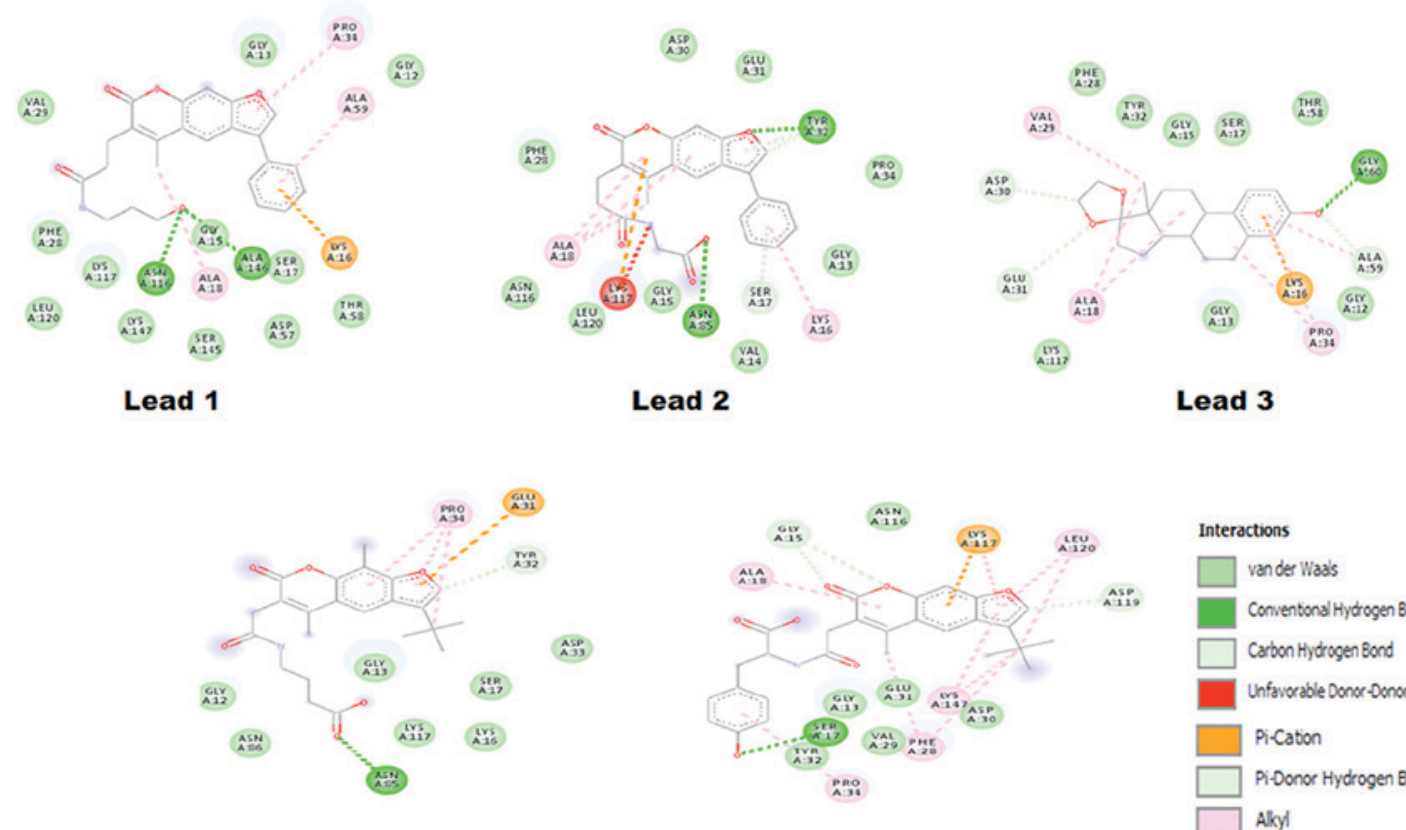

Lead 4
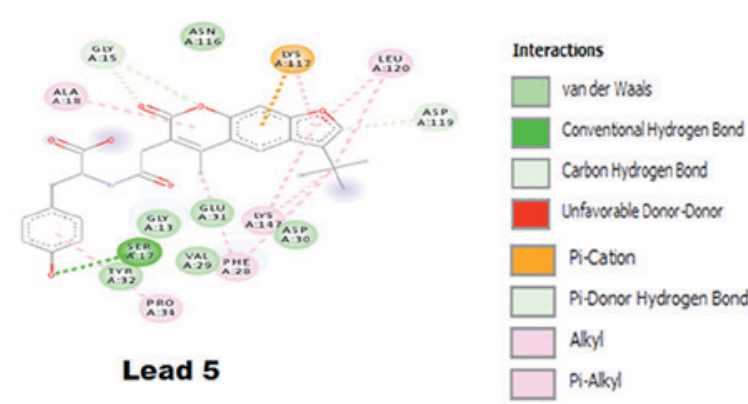

Figure 5. Two-dimensional representation of the binding pocket of the top five identified compounds with Ras.

binding pocket of Ras. The binding pocket of Lead5 was comprised of ASP119, LEU120, LYS117, ASN116, GLY15, ALA18, TYR32, PRO34, SER17, GLY13, VAL29, PHE28, GLU31, LYS147, PHE28 and ASP30.

The analysis in the present study observed that Lead3 was compound with the best $\mathrm{BBB}$ and $\mathrm{PPB}$, as well as the lowest $\Delta G$ value, and was thus selected for further analysis. In order to explore the stability and binding mode of Lead3 with the GTP binding site of Ras, MDS was performed for a $100 \mathrm{nsec}$ run under GROMOS 43a1 force field on the energy-minimized Lead3-Ras complex. The comparative RMSD plot was analyzed to examine the stability of this complex over time, and this plot revealed a substantial decrease in the RMSD of the complex throughout the simulation (Fig. 6). Furthermore, the dominant motions of the Lead3-Ras complex were also investigated using the PCA tool. The free energy landscape was plotted in order to retrieve the lowest energy conformer $(\mathrm{t}=67,324 \mathrm{psec})$. Subsequently, the retrieved structure of the 


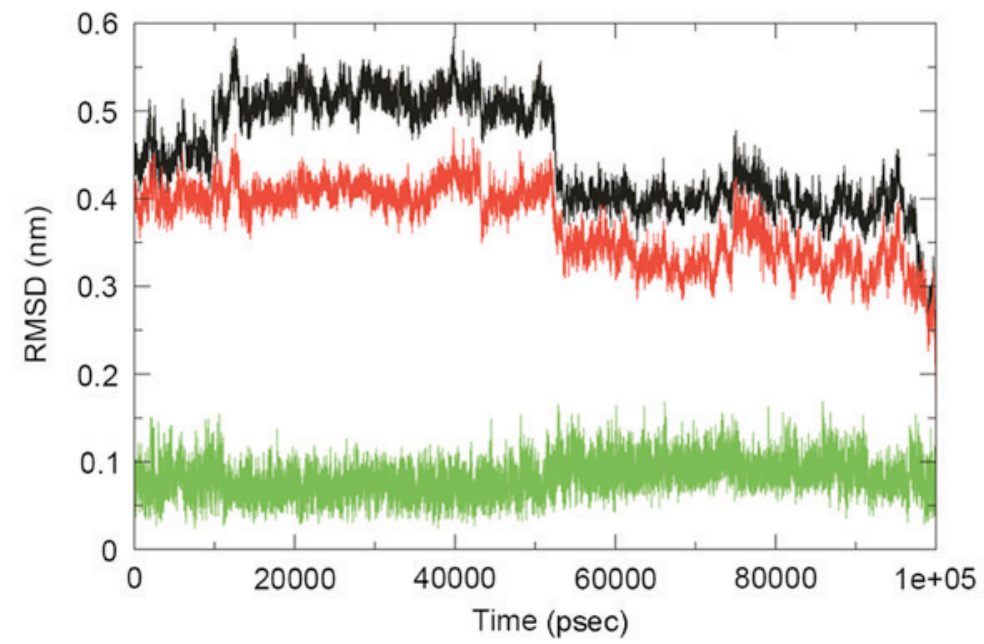

Figure 6. RMSD plot of Ras, the Ras-Lead3 complex and Lead3. Ras (black), Ras-Lead3 complex (red) and Lead3 compound (green). RMSD, root-mean-square deviation.
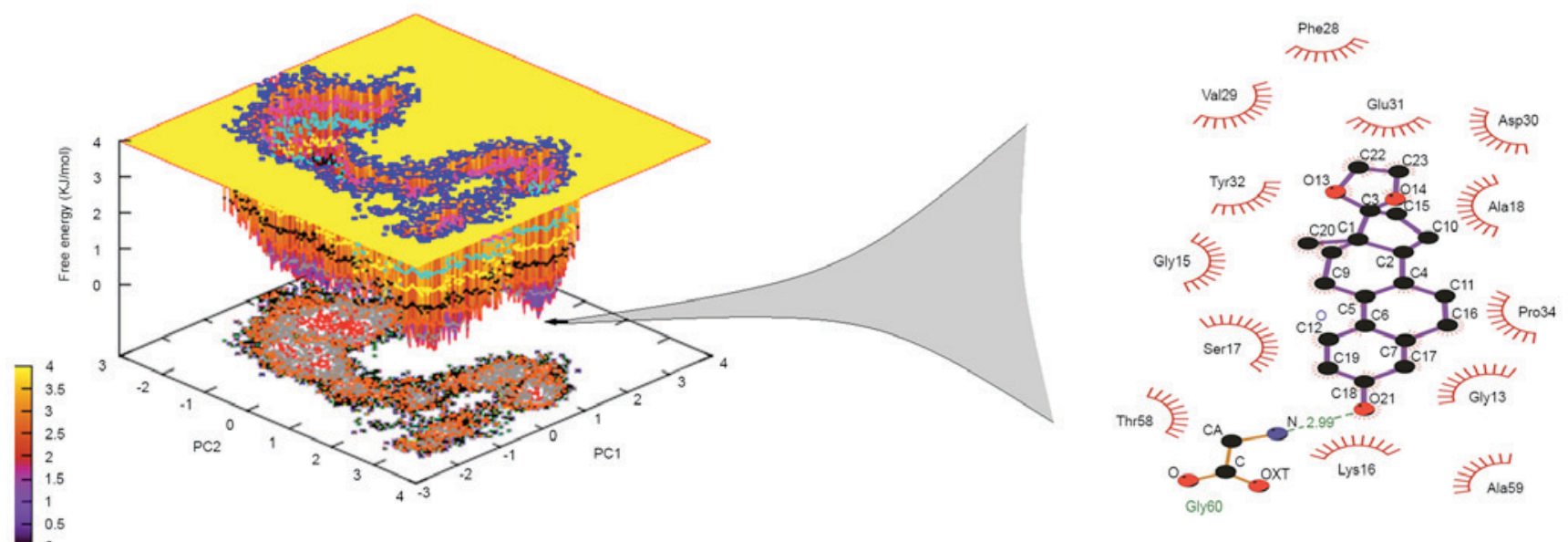

Figure 7. Free energy landscape (inverted) projection of the principal component analysis of the first (PC1) and second (PC2) principal eigenvectors for the backbone of Ras-Lead3 complex. The lowest energy conformer is presented, and the structure retrieved demonstrates a respective hydrogen bond pattern with atomic details. PC, principal component; OXT, terminal oxygen atom; CA, carbon atom.

Table IV. Molecular mechanics poisson-bolzmann surface area calculations.

\begin{tabular}{lc}
\hline Binding energy & Values $(\mathrm{kJ} / \mathrm{mol})$ \\
\hline Van der Waal & $-142.32 \pm 16.21$ \\
Electrostatic & $-6.51 \pm 1.31$ \\
Polar solvation & $44.87 \pm 7.89$ \\
Solvent accessible volume & $-102.32 \pm 18.61$ \\
Binding & $-189.33 \pm 28.22$
\end{tabular}

complex was used investigate the interactions at that time point, as shown in Fig. 7. The MM-PBSA calculations revealed that, in the GTP binding site, GLY60 was the best binding site with Lead 3 over time, thus revealing the inhibitory property of Lead3. Table IV demonstrates the $\Delta \mathrm{G}$ of the simulated complex.
In patients with SCI, the Ras/Raf/ERK1/2 signaling pathway has been associated with the promotion of apoptosis in neural cells (39); small molecule inhibitors and other methods of modulating the Ras/Raf/ERK1/2 signaling pathway have become a promising target for the development of novel treatments for traumatic injuries to the nervous system. To the best of our knowledge, the present study is first to use structure-based drug design to identify a novel lead drug of natural origin as a small molecular inhibitor for modulating Ras/Raf/ERK signaling pathway. Inhibitors, including PD98059 and U0126, have been used in in vivo studies targeting the Ras/Raf/ERK1/2 signaling pathway (58).

In conclusion, the in silico approach used in the present study investigated the IBS database of $\sim 50,000$ compounds and identified a single compound that bound to the GTP binding site of Ras, thus downregulating of the Ras/Raf/ERK1/2 signaling pathway. The inhibition of this pathway is able to restore the neuronal migration, adhesion and dendritic spine development. A chemical-computational 
approach was adopted in the current study, focusing on the development of Ras inhibitors of a natural origin that may prevent neuronal apoptosis in SCI, using used computer-aided drug designing approaches. The Ras GTP inhibitor proposed in the present study can be developed into a drug in further studies; thus, these findings provide a starting point for the development of a drug that may have a potential effect in the treatment of SCI. However, further in vitro and in vivo studies are required to translate the proposed lead compound into a potential drug.

\section{References}

1. Schwartz G and Fehlings MG: Evaluation of the neuroprotective effects of sodium channel blockers after spinal cord injury: Improved behavioral and neuroanatomical recovery with riluzole. J Neurosurg 94 (2 Suppl): 245-256, 2001.

2. Dobkin BH and Havton LA: Basic advances and new avenues in therapy of spinal cord injury. Annu Rev Med 55: 255-282, 2004.

3. Sekhon LH and Fehlings MG: Epidemiology, demographics, and pathophysiology of acute spinal cord injury. Spine (Phila Pa 1976) 26 (24 Suppl): S2-S12, 2001.

4. Harvey C, Wilson SE, Greene CG, Berkowitz M and Stripling TE: New estimates of the direct costs of traumatic spinal cord injuries: Results of a nationwide survey. Paraplegia 30: 834-850, 1992.

5. Albin MS and White RJ: Epidemiology, physiopathology, and experimental therapeutics of acute spinal cord injury. Crit Care Clin 3: 441-452, 1987.

6. Porter R: The Cambridge illustrated history of medicine. Cambridge Univ Press: 400, 2001.

7. Silva NA, Sousa N, Reis RL and Salgado AJ: From basics to clinical: A comprehensive review on spinal cord injury. Prog Neurobiol 114: 25-57, 2014.

8. Cadotte DW and Fehlings MG: Spinal cord injury: A systematic review of current treatment options. Clin Orthop Relat Res 469: 732-741, 2011.

9. Budh CN and Osteråker AL: Life satisfaction in individuals with a spinal cord injury and pain. Clin Rehabil 21: 89-96, 2007.

10. Varma AK, Das A, Wallace G IV, Barry J, Vertegel AA, Ray SK and Banik NL: Spinal cord injury: A review of current therapy, future treatments, and basic science frontiers. Neurochem Res 38: 895-905, 2013.

11. Bracken MB: Steroids for acute spinal cord injury. Cochrane Database Syst Rev 1: CD001046, 2012.

12. Bracken MB, Collins WF, Freeman DF, Shepard MJ, Wagner FW, Silten RM, Hellenbrand KG, Ransohoff J, Hunt WE, Perot PL Jr, et al: Efficacy of methylprednisolone in acute spinal cord injury. JAMA 251: 45-52, 1984.

13. Bracken MB, Shepard MJ, Collins WF Jr, Holford TR, Baskin DS, Eisenberg HM, Flamm E, Leo-Summers L, Maroon JC, Marshall LF, et al: Methylprednisolone or naloxone treatment after acute spinal cord injury: 1-year follow-up data. results of the second national acute spinal cord injury study. J Neurosurg 76: 23-31, 1992.

14. Bracken MB, Shepard MJ, Collins WF, Holford TR, Young W, Baskin DS, Eisenberg HM, Flamm E, Leo-Summers L, Maroon J, et al: A randomized, controlled trial of methylprednisolone or naloxone in the treatment of acute spinal-cord injury: Results of the second national acute spinal cord injury study. N Engl J Med 322: 1405-1411, 1990.

15. Tator $\mathrm{CH}$ : Review of treatment trials in human spinal cord injury: Issues, difficulties, and recommendations. Neurosurgery 59: 957-987, 2006

16. Chvatal SA,Kim YT, Bratt-Leal AM,Lee H and Bellamkonda RV: Spatial distribution and acute anti-inflammatory effects of methylprednisolone after sustained local delivery to the contused spinal cord. Biomaterials 29: 1967-1975, 2008.

17. Das A, Smith JA, Gibson C, Varma AK, Ray SK and Banik NL: Estrogen receptor agonists and estrogen attenuate TNF- $\alpha$-induced apoptosis in VSC4.1 motoneurons. J Endocrinol 208: 171-182, 2011.

18. Bains $M$ and Hall ED: Antioxidant therapies in traumatic brain and spinal cord injury. Biochim Biophys Acta 1822: 675-684, 2012.
19. Rong W, Wang J, Liu X, Jiang L, Wei F, Zhou H, Han X and Liu Z: $17 \beta$-estradiol attenuates neural cell apoptosis through inhibition of JNK phosphorylation in SCI rats and excitotoxicity induced by glutamate in vitro. Int J Neurosci 122: 381-387, 2012.

20. Lutton C, Young YW, Williams R, Meedeniya AC, Mackay-Sim A and Goss B: Combined VEGF and PDGF treatment reduces secondary degeneration after spinal cord injury. J Neurotrauma 29: 957-970, 2012.

21. Ray SK, Samantaray S, Smith JA, Matzelle DD, Das A and Banik NL: Inhibition of cysteine proteases in acute and chronic spinal cord injury. Neurotherapeutics 8: 180-186, 2011.

22. Lee JY,Choi SY,Oh TH and Yune TY: $17 \beta$-Estradiol inhibits apoptotic cell death of oligodendrocytes by inhibiting RhoA-JNK3 activation after spinal cord injury. Endocrinology 153: 3815-3827, 2012.

23. Samantaray S, Smith JA, Das A, Matzelle DD, Varma AK, Ray SK and Banik NL: Low dose estrogen prevents neuronal degeneration and microglial reactivity in an acute model of spinal cord injury: Effect of dosing, route of administration, and therapy delay. Neurochem Res 36: 1809-1816, 2011.

24. Wang YF, Fan ZK, Cao Y, Yu DS, Zhang YQ and Wang YS: 2-Methoxyestradiol inhibits the up-regulation of AQP4 and AQP1 expression after spinal cord injury. Brain Res 1370: 220-226, 2011

25. Knoller N, Auerbach G, Fulga V, Zelig G, Attias J, Bakimer R, Marder JB, Yoles E, Belkin M, Schwartz M and Hadani M: Clinical experience using incubated autologous macrophages as a treatment for complete spinal cord injury: Phase I study results. J Neurosurg Spine 3: 173-181, 2005.

26. Xu D, Cao F, Sun S, Liu T and Feng S: Inhibition of the Ras/Raf/ERK1/2 signaling pathway restores cultured spinal cord-injured neuronal migration, adhesion, and dendritic spine development. Neurochem Res 41: 2086-2096, 2016.

27. Bonni A, Brunet A, West AE, Datta SR, Takasu MA and Greenberg ME: Cell survival promoted by the Ras-MAPK signaling pathway by transcription-dependent and -independent mechanisms. Science 286: 1358-1362, 1999.

28. Chan KM, Gordon T, Zochodne DW and Power HA: Improving peripheral nerve regeneration: From molecular mechanisms to potential therapeutic targets. Exp Neurol 261: 826-835, 2014.

29. Mazzoni IE, Saïd FA, Aloyz R, Miller FD and Kaplan D: Ras regulates sympathetic neuron survival by suppressing the p53-mediated cell death pathway. J Neurosci 19: 9716-9727, 1999.

30. Liu ZD, Zhang S, Hao JJ, Xie TR and Kang JS: Cellular model of neuronal atrophy induced by DYNC1I1 deficiency reveals protective roles of RAS-RAF-MEK signaling. Protein Cell 7: 638-650, 2016.

31. Kanno H, Ozawa H, Sekiguchi A, Yamaya S, Tateda S, Yahata K and Itoi E: The role of mTOR signaling pathway in spinal cord injury. Cell Cycle 11: 3175-3179, 2012.

32. Namikawa K, Honma M, Abe K, Takeda M, Mansur K, Obata T, Miwa A, Okado H and Kiyama H: Akt/protein kinase B prevents injury-induced motoneuron death and accelerates axonal regeneration. J Neurosci 20: 2875-2886, 2000.

33. Sun Z, Wen Y, Mao Q, Hu L, Li H, Sun Z and Wang D: Adenosine-triphosphate promoting repair of spinal cord injury by activating mammalian target of rapamycin/signal transducers and activators of transcription 3 signal pathway in rats. Zhongguo Xiu Fu Chong Jian Wai Ke Za Zhi 24: 165-171, 2010 (In Chinese).

34. Liu A, Prenger MS, Norton DD, Mei L, Kusiak JW and Bai G: Nerve growth factor uses Ras/ERK and phosphatidylinositol 3-kinase cascades to up-regulate the N-methyl-D-aspartate receptor 1 promoter. J Biol Chem 276: 45372-45379, 2001.

35. Liu T, Cao FJ, Xu Dd, Xu YQ and Feng SQ: Upregulated Ras/Raf/ERK1/2 signaling pathway: A new hope in the repair of spinal cord injury. Neural Regen Res 10: 792-796, 2015.

36. Lo LW, Cheng JJ, Chiu JJ, Wung BS, Liu YC and Wang DL: Endothelial exposure to hypoxia induces Egr-1 expression involving PKCalpha-mediated Ras/Raf-1/ERK1/2 pathway. J Cell Physiol 188: 304-312, 2001.

37. Stanciu M, Wang Y, Kentor R, Burke N, Watkins S, Kress G, Reynolds I, Klann E, Angiolieri MR, Johnson JW and DeFranco DB: Persistent activation of ERK contributes to glutamate-induced oxidative toxicity in a neuronal cell line and primary cortical neuron cultures. J Biol Chem 275: 12200-12206, 2000.

38. Cao F, Zhang X, Liu T, Li XW, Malik M and Feng SQ: Up-regulation of Ras/Raf/ERK1/2 signaling in the spinal cord impairs neural cell migration, neurogenesis, synapse formation, and dendritic spine development. Chin Med J (Engl) 126: 3879-3885, 2013. 
39. Yang K, Cao F, Sheikh AM, Malik M, Wen G, Wei H, Ted Brown W and Li X: Up-regulation of Ras/Raf/ERK1/2 signaling impairs cultured neuronal cell migration, neurogenesis, synapse formation, and dendritic spine development. Brain Struct Funct 218: 669-682, 2013.

40. Chikan NA, Bhavaniprasad V, Anbarasu K, Shabir N and Patel TN From natural products to drugs for epimutation computer-aided drug design. Appl Biochem Biotechnol 170: 164-175, 2013.

41. Amin A, Chikan NA, Mokhdomi TA, Bukhari S, Koul AM, Shah BA, Gharemirshamlu FR, Wafai AH, Qadri A and Qadri RA: Irigenin, a novel lead from Western Himalayan chemiome inhibits fibronectin-extra domain a induced metastasis in lung cancer cells. Sci Rep 6: 37151, 2016.

42. Zhao GF, Huang ZA, Du XK, Yang ML, Huang DD and Zhang S: Molecular docking studies of traditional chinese medicinal compounds against known protein targets to treat non-small cell lung carcinomas. Mol Med Rep 14: 1132-1138, 2016.

43. van Gunsteren WF (ed): Biomolecular Simulation: The GROMOS96 Manual and User Guide, Biomos, Zürich, p757, 1996.

44. Trott $\mathrm{O}$ and Olson AJ: AutoDock Vina: Improving the speed and accuracy of docking with a new scoring function, efficient optimization, and multithreading. J Comput Chem 31: 455-461, 2010.

45. Lipinski CA: Lead- and drug-like compounds: The rule-of-five revolution. Drug Discov Today Technol 1: 337-341, 2004

46. Morris GM, Huey R, Lindstrom W, Sanner MF, Belew RK, Goodsell DS and Olson AJ: AutoDock4 and AutoDockTools4: Automated docking with selective receptor flexibility. J Comput Chem 30: 2785-2791, 2009.

47. Berendsen HJ, van der Spoel D and van Drunen R: GROMACS: A message-passing parallel molecular dynamics implementation. Com Phy Commun 91: 43-56, 1995.

48. Schüttelkopf AW and Van Aalten DM: PRODRG: A tool for high-throughput crystallography of protein-ligand complexes. Acta Crystallogr D Biol Crystallogr 60: 1355-1363, 2004
49. Darden T, York D and Pedersen L: Particle mesh Ewald: An $\mathrm{N}-\log (\mathrm{N})$ method for Ewald sums in large systems. J Chem Phy 98: 10089-10092, 1993.

50. Kholmurodov K, Smith W, Yasuoka K, Darden T and Ebisuzaki T: A smooth-particle mesh Ewald method for DL_POLY molecular dynamics simulation package on the Fujitsu VPP700. J Com Chem 21: 1187-1191, 2000.

51. Hess B, Kutzner C, Van Der Spoel D and Lindahl E: GROMACS 4: Algorithms for highly efficient, load-balanced, and scalable molecular simulation. J Chem Theory Comput 4: 435-447, 2008

52. Kumari R and Kumar R; Open Source Drug Discovery Consortium; Lynn A: g mmpbsa - a GROMACS tool for high-throughput MM-PBSA calculations. J Chem Inf Model 54: 1951-1962, 2014

53. DeLano WL (ed): The PyMOL Molecular Graphics System. DeLano Scientific, Palo Alto, CA, 2002.

54. Studio D: Accelrys Inc. San Diego, CA, USA, 2013.

55. Turner PJ (ed): XMGRACE, Version 5.1.19. Center for Coastal and Land-Margin Research. Oregon Graduate Institute of Science and Technology, Beaverton, OR, 2005.

56. Racine J: Gnuplot 4.0: A portable interactive plotting utility. J Appl Econome 21: 133-141, 2006.

57. Lin B, Xu Y, Zhang B, He Y, Yan Y and He MC: MEK inhibition reduces glial scar formation and promotes the recovery of sensorimotor function in rats following spinal cord injury. Exp Ther Med 7: 66-72, 2014.

58. Chen J, Rusnak M, Lombroso PJ and Sidhu A: Dopamine promotes striatal neuronal apoptotic death via ERK signaling cascades. Eur J Neurosci 29: 287-306, 2009.

This work is licensed under a Creative Commons

Attribution-NonCommercial-NoDerivatives 4.0

International (CC BY-NC-ND 4.0) License. 